\title{
Horizontal Gene Transfer Contributes to Plant Evolution: The Case of Agrobacterium T-DNAs
}

\author{
Dora G. Quispe-Huamanquispe ${ }^{1,2}$, Godelieve Gheysen ${ }^{1}$ and Jan F. Kreuze ${ }^{2 *}$ \\ ${ }^{1}$ Department of Molecular Biotechnology, Ghent University, Ghent, Belgium, ${ }^{2}$ International Potato Center (CIP), Lima, Peru
}

\section{OPEN ACCESS}

Edited by:

Tatiana Matveeva,

Saint Petersburg State University,

Russia

Reviewed by:

Katharina Pawlowski,

Stockholm University, Sweden

Nikolai Ravin,

Institute of Bioengineering, Research

Center for Biotechnology Russian Academy of Sciences, Russia

*Correspondence: Jan F. Kreuze

j.kreuze@cgiar.org

Specialty section:

This article was submitted to

Plant Microbe Interactions,

a section of the journal

Frontiers in Plant Science

Received: 24 May 2017 Accepted: 13 November 2017 Published: 24 November 2017

Citation:

Quispe-Huamanquispe DG,

Gheysen G and Kreuze JF (2017) Horizontal Gene Transfer Contributes

to Plant Evolution: The Case

of Agrobacterium T-DNAs.

Front. Plant Sci. 8:2015.

doi: 10.3389/fpls.2017.02015
Horizontal gene transfer (HGT) can be defined as the acquisition of genetic material from another organism without being its offspring. HGT is common in the microbial world including archaea and bacteria, where HGT mechanisms are widely understood and recognized as an important force in evolution. In eukaryotes, HGT now appears to occur more frequently than originally thought. Many studies are currently detecting novel HGT events among distinct lineages using next-generation sequencing. Most examples to date include gene transfers from bacterial donors to recipient organisms including fungi, plants, and animals. In plants, one well-studied example of HGT is the transfer of the tumor-inducing genes (T-DNAs) from some Agrobacterium species into their host plant genomes. Evidence of T-DNAs from Agrobacterium spp. into plant genomes, and their subsequent maintenance in the germline, has been reported in Nicotiana, Linaria and, more recently, in /pomoea species. The transferred genes do not produce the usual disease phenotype, and appear to have a role in evolution of these plants. In this paper, we review previous reported cases of HGT from Agrobacterium, including the transfer of T-DNA regions from Agrobacterium spp. to the sweetpotato [/pomoea batatas (L.) Lam.] genome which is, to date, the sole documented example of a naturally-occurring incidence of HGT from Agrobacterium to a domesticated crop plant. We also discuss the possible evolutionary impact of T-DNA acquisition on plants.

Keywords: HGT (horizontal gene transfer), Agrobacterium, Ipomoea batatas (L.) Lam., T-DNAs, evolution

\section{INTRODUCTION}

Horizontal gene transfer (HGT) can be defined as the acquisition of genetic material from another organism without being its offspring. It contrasts with vertical gene transfer, which is the acquisition of genetic material from an ancestor. HGT is a universal phenomenon and occurs frequently among prokaryotes. Bacteria have acquired a variety of important traits including antibiotic resistance, pathogenesis and metabolic pathways, via HGT. These horizontal gene acquisitions enabled bacteria to explore new habitats and hence facilitated their rapid evolution (Maiden, 1998; Ochman et al., 2000; Gogarten et al., 2002; Hotopp et al., 2007). In contrast to its rather common occurrence in prokaryotes, examples of HGT in eukaryotes have been reported only infrequently. However, that appears to be changing as recent discoveries indicate the possible contribution of HGT to the acquisition of traits with adaptive significance, suggesting that HGT is an important driving force in the evolution of eukaryotes, as well as prokaryotes. In this paper, we review HGT in higher organisms emphasizing examples involving Agrobacterium species and plants. We also discuss the possible evolutionary impact of the transferred genes on their respective hosts. 


\section{HGT IN EUKARYOTES}

Horizontal gene transfer played a pivotal role in the origin of eukaryotes. Endosymbiosis and the subsequent genetic integration of entire organisms gave rise to the mitochondria and plastids (Talianova and Janousek, 2011). Advances in sequencing technologies in combination with ever increasing amounts of sequence data have facilitated the identification of additional examples of HGT in eukaryotes. In most instances, these were identified by chance while sequencing for other purposes or as a result of phylogenetic incongruences while attempting to establish evolutionary relationships. Examples include DNA transfer from bacteria, fungi and plants to bdelloid rotifers (Gladyshev et al., 2008), bacteria to insects (Hotopp et al., 2007), bacteria and fungi to nematodes (Noon and Baum, 2016), fish to fish (Graham et al., 2008), bryophytes to ferns (Li et al., 2014), and bacteria to plants (White et al., 1983; Matveeva and Lutova, 2014; Kyndt et al., 2015).

A particularly interesting example of HGT is the transfer of fungal genes to the pea aphid (Acyrthosiphon pisum) (Moran and Jarvik, 2010). Genes coding for carotenoid synthase/cyclase and carotenoid desaturase enzymes had not been reported in animals until their discovery in the pea aphid genome. Carotenoid biosynthesis genes are responsible for the body pigmentation in pea aphids. Body color is considered an ecologically important trait that influences the susceptibility of pea aphids to predators and/or parasites. Ladybugs (Coccinellidae) prefer to attack red aphids while parasitic wasps are more likely to lay their eggs in green aphids. Phylogenetic analysis of these genes in the pea aphid (Nováková and Moran, 2012) indicated that they had been obtained from fungi. Further analyses suggested that these genes were acquired early in the radiation of this group (Nováková and Moran, 2012).

Despite being one of the oldest groups of land plants, the majority of living ferns resulted from a relatively recent diversification following the arrival of angiosperms. In order to exploit the new understory habitats created by angiosperm dominated ecosystems, ferns evolved strategies to thrive under the low light conditions created by the angiosperm canopy. In adapting to these conditions, ferns acquired an unconventional chimeric photoreceptor, called neochrome, that fuses red sensing phytochrome and blue sensing phototropin modules into a single gene, thereby optimizing phototropic responses (Li et al., 2014). The recent analysis of 434 transcriptomes and 40 genomes of plants and algae demonstrated that ferns acquired this gene from hornworts (a bryophyte lineage) via HGT about 179 million year ago (Li et al., 2014).

Horizontal gene transfer seems to have played an important role also in the transition from the aquatic to the terrestrial environment. A novel genome analyses of the moss Physcomitrella patens reveal that 57 families of nuclear genes were acquired by HGT from prokaryotes, fungi or viruses. These genes have strong implications on plant-specific activities, such as xylem formation, plant defense, and hormone biosynthesis. The study suggests that many of these genes were transferred to the ancestors of green or land plants (Yue et al., 2012). Other examples of HGT in plants involve the case of parasitic plants (Yang et al., 2016). The transcriptome analyses of three parasitic members of Orobanchaceae family show the occurrence of 52 high-confidence HGT events. Genes acquired by HGT are preferentially expressed in the haustorium, the host connecting organ of parasitic plants, proposing that these genes are contributing to the unique adaptive feeding structure of parasitic plants.

\section{HGT FROM Agrobacterium SPECIES TO PLANTS (THE CLASSICAL MODEL)}

Agrobacterium-mediated plant genetic transformation is probably the best studied and best understood system of transkingdom gene transfer. Agrobacterium is a plant pathogenic bacterium that causes neoplastic growth, i.e., uncontrolled cell division in host plants resulting in crown galls or in proliferating roots following the transfer of a segment of its DNA into the host cell genome.

Most of the bacterial genes necessary for the DNA transfer are located in a large tumor- or root-inducing plasmid (Ti/Ri plasmid) which also contains that part of the plasmid that is transferred (T-DNA). During Agrobacterium infection, plantderived phenolics trigger the expression of the bacterium's virulence genes, and the encoded proteins subsequently mediate the T-DNA transfer to the host plant cell. The final destiny of the T-DNA in the host cell is dependent on various interactions between Agrobacterium and plant proteins. Several host cell pathways are utilized to ensure that the T-DNA is imported to the nucleus and integrated into the host genome (Lacroix and Citovsky, 2016). Expression of the T-DNA genes in the plant can alter the physiology to stimulate cell division and root growth. IaaM and iaaH encode enzymes for the biosynthesis of auxin that is essential for crown gall development (Zhang et al., 2015). Several rol (root loci) genes are involved in root formation while the function of several T-DNA genes such as C-prot is still unknown (Otten et al., 1999). Opines are also encoded on the T-DNAs, they are utilized as carbon and nitrogen sources by invading bacteria and their presence can alter the biological root environment, particularly, root associated bacterial populations (Oger et al., 1997). Acs encodes the key enzyme for the biosynthesis of the opine called agrocinopine while $m i s$ is a mikimopine synthase and mas a mannopine synthase.

The ability of Agrobacterium to transform plants has been exploited for decades as a means to introduce foreign genes of interest into crop plants (Tzfira and Citovsky, 2006; Gelvin, 2009). However, Agrobacterium-mediated HGT is not restricted to the production of genetically modified crops. Evidence of the naturally occurring transfer of T-DNA genes from Agrobacterium into plant genomes and their subsequent maintenance in the germline has been documented in Nicotiana, Linaria, and more recently Ipomoea species Figure 1 (White et al., 1983; Intrieri and Buiatti, 2001; Matveeva et al., 2012; Pavlova et al., 2014; Kyndt et al., 2015). In these examples, the transferred genes are fixed and are expressed in the host plant's lineage suggesting that they might have a functional role. 


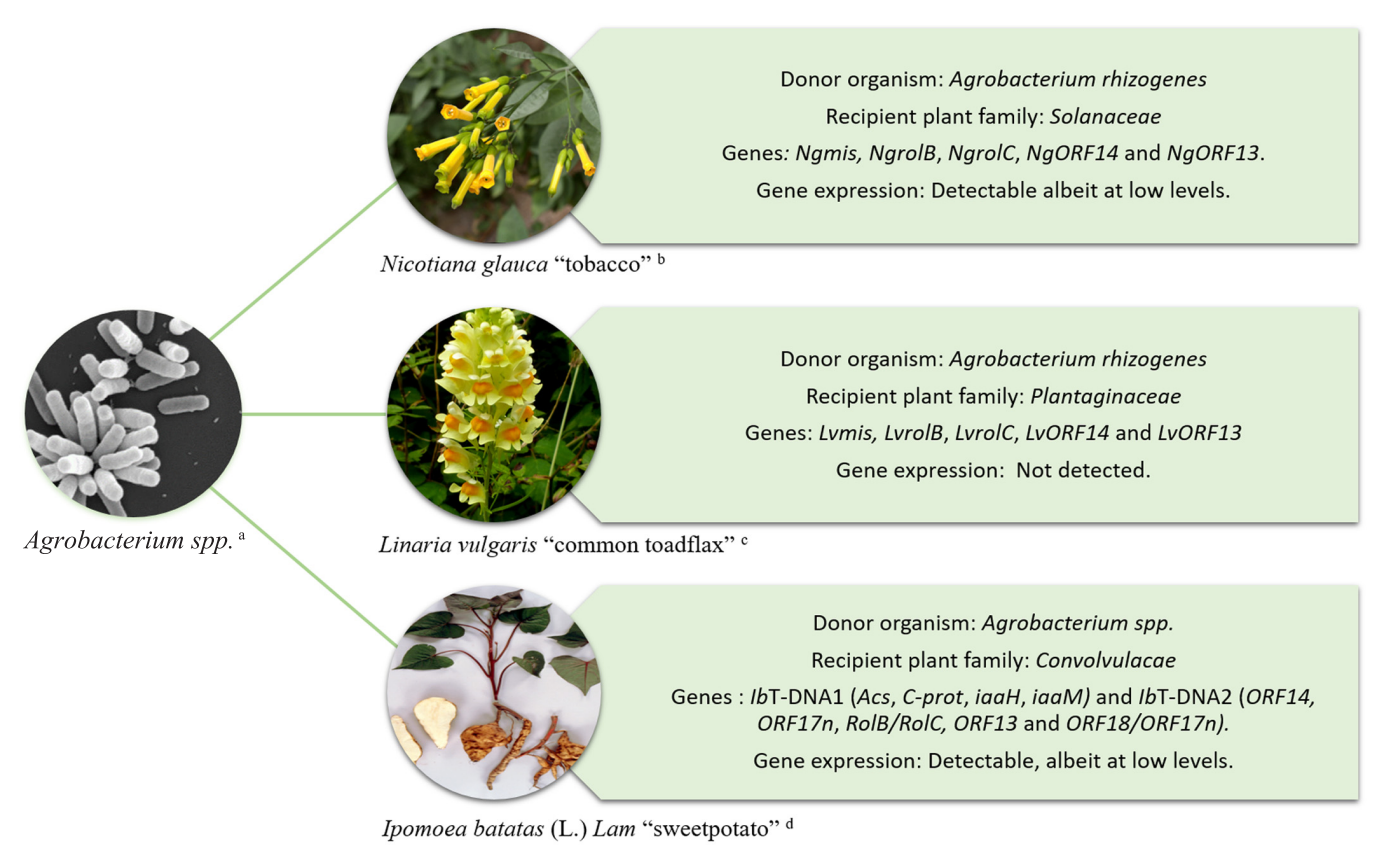

FIGURE 1 | Schematic representation of HGT from Agrobacterium to plants. Examples include; Nicotiana glauca "tobacco" (White et al., 1983) - upper right, Linaria vulgaris "common toadflax" (Matveeva et al., 2012) - middle right, and Ipomoea batatas (L.) Lam "sweet potato" (Kyndt et al., 2015) - lower right. Imagens courtesy of (a) Jing Xu, Indiana University, (b) A. H. Harris, Texas University at El Paso, (c) Graham Calow, NatureSpot (http://www.naturespot.org.uk/species/commontoadflax), and (d) International Potato Center (CIP).

\section{HGT FROM Agrobacterium rhizogenes TO Nicotiana AND Linaria}

More than three decades ago White et al. (1983) detected a region in the genome of Nicotiana glauca homologous to regions in the T-DNA of the Ri plasmid of Agrobacterium rhizogenes. The region was called cellular T-DNA (cT-DNA) (White et al., 1983). The cT-DNA in the $N$. glauca genome was initially described as an imperfect inverted repeat that contained two homologs to rol genes, NgrolB and NgrolC (Ng, N. glauca). Later, the cT-DNA was found to contain two additional genes corresponding to open reading frames ORF13 and ORF14 (Aoki et al., 1994). The discovery of mikimopine synthase ( $m i s$ ) sequences ( $N g m i s L$ and NgmisR) in the N. glauca cT-DNA indicated that it originated from a mikimopine-type Ri plasmid (Suzuki et al., 2002).

PCR analysis and southern hybridization confirmed the acquisition of cT-DNA by N. glauca (Furner et al., 1986). Intrieri and Buiatti (2001) screened a total of 42 Nicotiana species for the presence of $\mathrm{rolB}$, rolC, ORF13 and ORF14, and at least one of those genes was detected in the genome of 15 species. Phylogenetic analyses concluded that the rol genes seemed to follow the evolution of the genus Nicotiana. This study (Intrieri and Buiatti, 2001) also suggested that more than one independent infection of Nicotiana by $A$. rhizogenes occurred in ancient times. This hypothesis was recently corroborated through deep sequencing of the genome of the ancestral tobacco species Nicotiana tomentosiformis (Chen et al., 2014). The genome of $N$. tomentosiformis contains four cT-DNAs all of which are derived from different Agrobacterium strains. These cT-DNAs,
TA, TB, TC, and TD, each contain an incomplete inverted-repeat structure. The TB region contains an intact mannopine synthase $2^{\prime}$ gene (TB- mas $2^{\prime}$ ) that is highly expressed in roots of some $N$. tabacum cultivars. These results suggest that the TB-mas $2^{\prime}$ gene could have been selected in some tobacco populations by nature or by tobacco growers, as a result of changes in the root metabolism of these plants (Chen et al., 2016).

cT-DNA sequences are not restricted to the genus Nicotiana. Indeed, they have also been found in species belonging to the genus Linaria, primarily within sections Linaria and Speciosae (Pavlova et al., 2014). Two copies of cT-DNA are present in Linaria vulgaris and are imperfect direct repeats. The Linaria cT-DNA appears to have originated from an ancient infection by a mikimopine strain of $A$. rhizogenes. Among the cT-DNA genes, rolC is the most conserved gene in the Linaria group and it contains an intact ORF. However, reverse transcriptional (RT) real-time PCR assays carried out using L. vulgaris internodes, leaves and roots under in vitro conditions have shown that rolC and the other cT-DNA genes are not expressed in these tissues (Matveeva et al., 2012).

\section{HGT FROM Agrobacterium TO Ipomoea spp.}

Sweet potato [Ipomoea batatas (L.) Lam.] belongs to genus Ipomoea. Ipomoea is the largest genus in the family Convolvulaceae and contains 600-700 species. Over half of Ipomoea spp. are concentrated in the Americas, where they are 
distributed as cultigens, medicinal plants and weeds (Huaman, 1992). Series Batatas is a small group of taxa within the genus Ipomoea that contains 13 species that are considered to be closely related to sweet potato (Nimmakayala et al., 2011). Members of this series include Ipomoea cordatotriloba, I. cynanchifolia, I. grandiflora, I. lacunosa, I. leucantha, I. littoralis, I. ramosissima, I. umbraticola, I. tabascana, I. tenuissima, I. tiliacea, I. trifida, and I. triloba. The basic chromosome number of the series is 15 whereas the cultivated sweet potato is a hexaploid species $(2 \mathrm{n}=6 \mathrm{x}=90)$. However, tetraploid $(2 \mathrm{n}=4 \mathrm{x}=60)$ variants of I. batatas have also been reported (Bohac et al., 1993; Roullier et al., 2013) and these are sometimes referred to as tetraploid I. trifida or wild sweet potatoes in the scientific literature. Today, sweet potato is a staple food crop in many areas of the world. However, its botanical origins and the details concerning its domestication remain obscure.

The discovery of Agrobacterium genes IbT-DNA1 and IbT-DNA2 in the sweet potato genome represents the only known example of an ancient HGT that occurred in, what is today, a domesticated crop (Kyndt et al., 2015). Both regions, $I b$ T-DNA1 and IbT-DNA2 were fortuitously detected during an analysis of small interfering RNA ( $s i R N A$ ) in the sweet potato cultivar Huachano. Plants of cv. Huachano contain an IbT-DNA1 with at least 4 ORFs with significant homology to the bacterial genes tryptophan-2-monooxygenase (iaaM), indole-3-acetamide hydrolase $(\mathrm{iaaH}), \mathrm{C}$-protein $(\mathrm{C}$-prot) and agrocinopine synthase (Acs) and an IbT-DNA2 containing at least five ORFs with significant homology to ORF14, ORF17n, RolB/RolC, ORF13, and $O R F 18 / O R F 17 n$. The insertion of IbT-DNA1 has been corroborated by sequence analysis of a bacterial artificial chromosome (BAC) clone of sweet potato cv. Xu781. The BAC sequence revealed that the complete $I b T$-DNA1 encompassed $21,564 \mathrm{bp}$ and consisted of an inverted repeat. IbT-DNA1 and 2 are transmitted from parent to progeny and the genes are expressed at detectable levels in different sweet potato tissues suggesting that they may have a function (Kyndt et al., 2015).

\section{THE EVOLUTIONARY IMPACT OF THE ACQUISITION OF T-DNAS IN PLANTS}

In general, for any foreign gene to be acquired by a host and stably inherited by its offspring (i) it must enter a cell and be integrated into the recipient genome, (ii) the DNA should not be lost after genome rearrangements during subsequent cell divisions, (iii) the transformed cell must enter the germ line, and finally (iv) the integrated sequence must be preserved in the course of evolution, which is most likely to happen if the gene confers a selective advantage to the recipient organism (Huang, 2013; Lacroix and Citovsky, 2016). In the case of T-DNA genes one could assume another specific requirement which is that the inserted genes must somehow be modified or controlled from their 'natural' expression pattern to avoid vigorous cell growth that would be detrimental to survival of the plant. The gold standard to determine gene function resulting from HGT is the existence of a phenotype that is correlated with the presence of those genes.
However, changes to the phenotype are not always so obvious and may in fact be difficult to detect.

The phenotypic effect of the Agrobacterium rol genes present in Nicotiana and I. batatas is likely associated with root traits (Matveeva et al., 2012; Kyndt et al., 2015). The suite of genes $\operatorname{rol} A, \operatorname{rolB}$, and rolC when transformed in tobacco plants, is able to induce the full "hairy root syndrome" (Maurel et al., 1991). RolA and rolB are mutated in N. tabacum, while rolC is intact. Transgenic tobacco plants bearing only rolC display phenotypic changes such as reduced apical dominance, dwarfism, shortened internodes, lanceolate leaves, and early flowering. They also exhibit increased root production when compared to untransformed plants (Shoja, 2010). The exact role of IbT-DNA genes remains to be elucidated, although is known that the larger part of $I b$ T-DNA1 and $I b$ T-DNA2 genes are intact and are expressed.

How plants have avoided the Agrobacterium programmed expression of T-DNA sequences after insertion into their genomes to avoid Agrobacterium programmed cell proliferation is not clear yet, but several options can be considered. The T-DNA may have integrated in a region of the genome that is transcriptionally inactive, a property which is subsequently imparted on the inserted T-DNA. On the other hand, in sweetpotato the IbT-DNAs were originally discovered by small RNA sequencing and assembly, indicating that the genes arranged in an inverted repeat- are targeted by the RNA silencing mechanism of the plant and in that way suppressed in their expression, even if they integrated in a transcriptionally active region of the genome (Kyndt et al., 2015). In the case of TB-mas2', evidence suggests that originally it was a functional gene but has lost its expression in N. tomentosiformis, perhaps due to gene silencing; whereas it is active in N. tabacum (Chen et al., 2016).

The production of storage roots and the ability to easily propagate via rooted vine cuttings are major traits associated with the domestication of the sweet potato. Considering that IbT-DNAs appear to be inherited from wild relatives and some IbT-DNA genes have the potential to change plant physiology (auxin biosynthesis or sensitivity), it is tempting to speculate that $I b$ T-DNAs have conferred an adaptive advantage to the host. A possible association between rolB/rolC genes and root parameters (total root yield, dry matter content, and harvest index) was evaluated in a population segregating for IbT-DNA2. No association between the occurrence of these genes and the noted root characteristics was detected, except for root yield at one location (Kyndt et al., 2015). Further study is required to establish the role, if any, of IbT-DNA2 genes in root development. To this end, a functional analysis using CRISPR-Cas9 to knockout single genes, combinations of genes, or the whole IbT-DNA1 and/or 2, would result in plants that could be analyzed in detail for their phenotype and developmental characteristics.

Knowledge of the timing of the ancestral infection as well as details about the infection process (such as whether it occurred as a single event or as multiple independent events), could shed light on the evolutionary impact of the cT-DNA and the IbTDNA sequences on Nicotiana and Ipomoea spp. In Nicotiana, the data suggest that Agrobacterium spp. infected this group multiple 
times, independently. Incongruences during the phylogenetic analyses of rolB in Nicotiana were the first evidence of this hypothesis (Intrieri and Buiatti, 2001; Suzuki et al., 2002) which is now gaining general acceptance. Indeed, the four cT-DNAs found in the ancestral tobacco species $N$. tomentosiformis appear to be derived from different Agrobacterium strains (Chen et al., 2016). In the sweet potato, IbT-DNA 1 and 2 are present at different loci and segregate independently, i.e., IbT-DNA1 seems to be fixed, while $I b$ T-DNA2 is restricted to only some accessions and segregates at random depending which genes are being analyzed. These differences may reflect different infection events. However, A. rhizogenes plasmids typically have two T-DNAs corresponding to $I b T$-DNA1 and 2 that are transferred independently but often simultaneously.

\section{FUTURE PERSPECTIVES}

Investigations about the role of Agrobacterium T-DNAs in the evolution of plants are only just beginning. Screening of additional Ipomoea species in our labs will demonstrate if T-DNA genes are confined to the cultivated sweet potato, or are also present in some of its wild relatives. The pattern of possible acquisition of $I b T$-DNAs by other Ipomoea species may help to formulate a hypothesis on the role that these sequences have

\section{REFERENCES}

Aoki, S., Kawaoka, A., Sekine, M., Ichikawa, T., Fujita, T., Shinmyo, A., et al. (1994). Sequence of the cellular T-DNA in the untransformed genome of Nicotiana glauca that is homologous to ORFs 13 and 14 of the Ri plasmid and analysis of its expression in genetic tumors of N. glauca x N. langsdorffi. Mol. Gen. Genet. 243, 706-710. doi: 10.1007/BF00279581

Bohac, J. R., Austin, D. F., and Jones, A. (1993). Discovery of wild tetraploid sweetpotatoes. Econ. Bot. 47, 193-201. doi: 10.1007/BF02862022

Chen, K., Borne, F. D., Julio, E., Obszynski, J., Pale, P., and Otten, L. (2016). Rootspecific expression of opine genes and opine accumulation in some cultivars of the naturally occurring genetically modified organism Nicotiana tabacum. Plant J. 87, 258-269. doi: 10.1111/tpj.13196

Chen, K., Dorlhac de Borne, F., Szegedi, E., and Otten, L. (2014). Deep sequencing of the ancestral tobacco species Nicotiana tomentosiformis reveals multiple T-DNA inserts and a complex evolutionary history of natural transformation in the genus Nicotiana. Plant J. 80, 669-682. doi: 10.1111/tpj.12661

Furner, I. J., Huffman, G. A., Amasino, R. M., Garfinkel, D. J., Gordon, M. P., and Nester, E. W. (1986). An Agrobacterium transformation in the evolution of the genus Nicotiana. Nature 319, 422-427. doi: 10.1038/319422a0

Gelvin, S. B. (2009). Agrobacterium in the genomics age. Plant physiol. 150, 1665-1676. doi: 10.1104/pp.109.139873

Gladyshev, E. A., Meselson, M., and Arkhipova, I. R. (2008). Massive horizontal gene transfer in bdelloid rotifers. Science 320, 1210-1213. doi: 10.1126/science. 1156407

Gogarten, J. P., Doolittle, W. F., and Lawrence, J. G. (2002). Prokaryotic evolution in light of gene transfer. Mol. Biol. Evol. 19, 2226-2238. doi: 10.1093/ oxfordjournals.molbev.a004046

Graham, L. A., Lougheed, S. C., Ewart, K. V., and Davies, P. L. (2008). Lateral transfer of a lectin-like antifreeze protein gene in fishes. PLOS ONE 3:e2616. doi: 10.1371/journal.pone.0002616

Hotopp, J. C. D., Clark, M. E., Oliveira, D. C., Foster, J. M., Fischer, P., Torres, M. C. M., et al. (2007). Widespread lateral gene transfer from intracellular bacteria to multicellular eukaryotes. Science 317, 1753-1756. doi: 10.1126/ science. 1142490 played in the evolution of this crop - and its related species. Although these genes are expressed at detectable levels in sweet potato, and some of them $(\mathrm{rolB} / \mathrm{rolC})$ are associated with root parameters, further analyses are needed in order to clarify their function(s).

\section{AUTHOR CONTRIBUTIONS}

DQ-H wrote the first draft and JK and GG subsequently contributed to produce the final version.

\section{ACKNOWLEDGMENTS}

The authors gratefully acknowledge the financial support provided to DQ-H from the Special Research Fund (BOF) of Ghent University, Belgium (01W02112) and Consejo Nacional de Ciencia, Tecnología e Innovación Tecnológica (CONCYTEC) of the government of Peru. We acknowledge Robert L. Jarret and León Otten for critical review of the manuscript. Research by JK was undertaken as part of, and funded by, the CGIAR Research Program on Roots, Tubers and Bananas (RTB) and supported by CGIAR Fund Donors (http://www.cgiar.org/aboutus/our-funders/).

Huaman, Z. (1992). Systematic Botany and Morphology of the Sweetpotato Plant. Lima: International Potato Center (CIP).

Huang, J. (2013). Horizontal gene transfer in eukaryotes: the weak-link model. Bioessays 35, 868-875. doi: 10.1002/bies.201300007

Intrieri, M. C., and Buiatti, M. (2001). The horizontal transfer of Agrobacterium rhizogenes genes and the evolution of the genus Nicotiana. Mol. Phylogenet. Evol. 20, 100-110. doi: 10.1006/mpev.2001.0927

Kyndt, T., Quispe, D., Zhai, H., Jarret, R., Ghislain, M., Liu, Q., et al. (2015). The genome of cultivated sweet potato contains Agrobacterium T-DNAs with expressed genes: an example of a naturally transgenic food crop. Proc. Natl. Acad. Sci. U.S.A. 112, 5844-5849. doi: 10.1073/pnas.1419685112

Lacroix, B., and Citovsky, V. (2016). Transfer of DNA from bacteria to eukaryotes. mBio 7:e00863-16. doi: 10.1128/mBio.00863-16

Li, F. W., Villarreal, J. C., Kelly, S., Rothfels, C. J., Melkonian, M., Frangedakis, E., et al. (2014). Horizontal transfer of an adaptive chimeric photoreceptor from bryophytes to ferns. Proc. Natl. Acad. Sci. U.S.A. 111, 6672-6677. doi: 10.1073/ pnas. 1319929111

Maiden, M. C. J. (1998). Horizontal genetic exchange, evolution, and spread of antibiotic resistance in bacteria. Clin. Infect. Dis. 27, S12-S20. doi: 10.1086/ 514917

Matveeva, T. V., Bogomaz, D. I., Pavlova, O. A., Nester, E. W., and Lutova, L. A. (2012). Horizontal gene transfer from genus Agrobacterium to the plant Linaria in nature. Mol. Plant Microbe Interact. 25, 1542-1551. doi: 10.1094/MPMI-0712-0169-R

Matveeva, T. V., and Lutova, L. A. (2014). Horizontal gene transfer from Agrobacterium to plants. Front. Plant Sci. 5:326. doi: 10.3389/fpls.2014.00326

Maurel, C., Barbier-Brygoo, H., Spena, A., Tempé, J., and Guern, J. (1991). Single rol genes from the Agrobacterium rhizogenes TL-DNA alter some of the cellular responses to auxin in Nicotiana tabacum. Plant Physiol. 97, 212-216.

Moran, N. A., and Jarvik, T. (2010). Lateral transfer of genes from fungi underlies carotenoid production in aphids. Science 328, 624-627. doi: 10.1126/science. 1187113

Nimmakayala, P., Vajja, G., and Reddy, U. K. (2011). "Ipomoea," in Wild Crop Relatives: Genomic and Breeding Resources, ed. C. Kole (Berlin: Springer), $123-132$. 
Noon, J. B., and Baum, T. J. (2016). Horizontal gene transfer of acetyltransferases, invertases and chorismate mutases from different bacteria to diverse recipients. BMC Evol. Biol. 16:74. doi: 10.1186/s12862-016-0651-y

Nováková, E., and Moran, N. A. (2012). Diversification of genes for carotenoid biosynthesis in aphids following an ancient transfer from a fungus. Mol. Biol. Evol. 29, 313-323. doi: 10.1093/molbev/msr206

Ochman, H., Lawrence, J. G., and Groisman, E. A. (2000). Lateral gene transfer and the nature of bacterial innovation. Nature 405, 299-304. doi: 10.1038/35012500

Oger, P., Petit, A., and Dessaux, Y. (1997). Genetically engineered plants producing opines alter their biological environment. Nat. Biotechnol. 15, 369-372. doi: 10.1038/nbt0497-369

Otten, L., Salomone, J.-Y., Helfer, A., Schmidt, J., Hammann, P., and De Ruffray, P. (1999). Sequence and functional analysis of the left-hand part of the T-region from the nopaline-type Ti plasmid, pTiC58. Plant Mol. Biol. 41, 765-776. doi: 10.1023/A:1006370207379

Pavlova, O., Matveeva, T., and Lutova, L. (2014). Genome of Linaria dalmatica contains Agrobacterium rhizogenes RolC gene homolog. Russ. J. Genet. Appl. Res. 4, 461-465. doi: 10.1134/S2079059714050116

Roullier, C., Duputié, A., Wennekes, P., Benoit, L., Bringas, V. M. F., Rossel, G., et al. (2013). Disentangling the origins of cultivated sweet potato (Ipomoea batatas (L.) Lam.). PLOS ONE 8:e62707. doi: 10.1371/journal.pone.0062707

Shoja, H. M. (2010). Contribution to the Study of the Agrobacterium rhizogenes Plast Genes, RolB and RolC, and Their Homologs in Nicotiana tabacum. Strasbourg: Universite de Strasbourg.

Suzuki, K., Yamashita, I., and Tanaka, N. (2002). Tobacco plants were transformed by Agrobacterium rhizogenes infection during their evolution. Plant J. 32, 775-787. doi: 10.1046/j.1365-313X.2002.01468.x

Talianova, M., and Janousek, B. (2011). What can we learn from tobacco and other Solanaceae about horizontal DNA transfer? Am. J. Bot. 98, 1231-1242. doi: 10.3732/ajb.1000370
Tzfira, T., and Citovsky, V. (2006). Agrobacterium-mediated genetic transformation of plants: biology and biotechnology. Curr. Opin. Biotechnol. 17, 147-154. doi: 10.1016/j.copbio.2006.01.009

White, F. F., Garfinkel, D. J., Huffman, G. A., Gordon, M. P., and Nester, E. W. (1983). Sequences homologous to Agrobacterium rhizogenes T-DNA in the genomes of uninfected plants. Nature 301, 348-350. doi: 10.1038/30 $1348 \mathrm{a} 0$

Yang, Z., Zhang, Y., Wafula, E. K., Honaas, L. A., Ralph, P. E., Jones, S., et al. (2016). Horizontal gene transfer is more frequent with increased heterotrophy and contributes to parasite adaptation. Proc. Natl. Acad. Sci. U.S.A. 113, E7010-E7019. doi: 10.1073/pnas.1608765113

Yue, J., Hu, X., Sun, H., Yang, Y., and Huang, J. (2012). Widespread impact of horizontal gene transfer on plant colonization of land. Nat. Commun. 3, 1152. doi: $10.1038 /$ ncomms 2148

Zhang, Y., Lee, C.-W., Wehner, N., Imdahl, F., Svetlana, V., Weiste, C., et al. (2015). Regulation of oncogene expression in T-DNA-transformed host plant cells. PLOS Pathog. 11:e1004620. doi: 10.1371/journal.ppat. 1004620

Conflict of Interest Statement: The authors declare that the research was conducted in the absence of any commercial or financial relationships that could be construed as a potential conflict of interest.

Copyright (C) 2017 Quispe-Huamanquispe, Gheysen and Kreuze. This is an openaccess article distributed under the terms of the Creative Commons Attribution License (CC BY). The use, distribution or reproduction in other forums is permitted, provided the original author(s) or licensor are credited and that the original publication in this journal is cited, in accordance with accepted academic practice. No use, distribution or reproduction is permitted which does not comply with these terms. 